\title{
Irradiation Treatment of Laryngeal Cancer in a Patient with an Implantable Cardioverter-Defibrillator (ICD)
}

\author{
Susanna Sepe Pamela Schaffer Klaus Krimmel Moshe Schaffer \\ Klinik und Poliklinik für Strahlentherapie und Radioonkologie, Ludwig-Maximilians-Universität München, Germany
}

Key Words

Cardioverter-defibrillator - Radiotherapy

\section{Summary}

Background: Due to an aging population the incidence of both cardiac and tumor-related illnesses is increasing. A problem may arise if radiotherapy is necessary in close anatomic proximity to an implantable cardioverter-defibrillator (ICD). These highly precise devices may respond to ionizing radiation with a loss of function or uncontrolled stimulation, with both effects being potentially life threatening. Available guidelines recommend the dose maximum to a pacemaker to be cumulative below $2 \mathrm{~Gy}$. For most patients undergoing radiation therapy of the neck or of the chest this limit is exceeded, thus making a removal of the device and an implantation of an external ICD necessary. Case Report: A patient with severe cardiac problems underwent an implantation of an ICD. However, a recurrence of a laryngeal cancer was diagnosed. The irradiation dose after resection was $60 \mathrm{~Gy}$ to the tumor region and $50 \mathrm{~Gy}$ to the lymph nodes. Irradiation peakload to the ICD was calculated to be $2.5 \mathrm{~Gy}$. This dose was verified with thermoluminescence measurements. The ICD was externally deactivated during the sessions of irradiation. Device checks demonstrated no malfunction. Conclusion: Even though the dose limits of the ICD of 2 Gy were exceeded, the device demonstrated a regular function during and after radiotherapy.
Schlüsselwörter

Schrittmacher mit Defibrillatorfunktion . Strahlentherapie

\section{Summary}

Hintergrund: In Anbetracht einer älter werdenden Bevölkerung steigt die Häufigkeit sowohl kardialer als auch tumorbedingter Erkrankungen. Problematisch wird es, wenn eine Strahlenbehandlung in anatomischer Nähe eines implantierten Schrittmachers mit integrierter Defibrillatorfunktion erfolgen muss. Diese hochpräzisen Aggregate können auf ionisierende Strahlung mit Funktionsverlust oder unkontrollierter Stimulation reagieren. Beides kann lebensbedrohlich sein. Verfügbare Richtlinien empfehlen, dass am Schrittmacher eine Dosis von kumulativ 2 Gy nicht überschritten werden soll. Bei den meisten Patienten, die sich einer Strahlenbehandlung im Kopf-Hals-Bereich unterziehen, wird diese Dosis überschritten, was eine Explantation und das Tragen eines externen Schrittmachers bzw. Defibrillators notwendig machen würde. Fallbericht: Einem Patienten mit Larynxkarzinom-Rezidiv wurde wegen schwerer kardialer Vorerkrankungen ein Schrittmacher mit Defibrillatorfunktion implantiert. Die postoperative Strahlendosis an der Rezidivregion betrug $60 \mathrm{~Gy}$, an den Lymphknoten 50 Gy. Im Vorfeld wurde die Strahlenbelastung am Aggregat mit 2,5 Gy berechnet und in vivo mittels Thermolumineszenzmessungen verifiziert. Während der Bestrahlungssitzungen wurde der Defibrillator extern deaktiviert. Regelmäßige Aggregatkontrollen zeigten keinen Gerätedefekt. Schlussfolgerung: Obwohl die Gesamtdosis von 2 Gy am Schrittmacher und Defibrillator überschritten wurde, zeigte das Aggregat während und nach der Strahlentherapie eine regelrechte Funktion.

\begin{tabular}{ll}
\hline KARGER & @ 2007 S. Karger GmbH, Freiburg \\
Fax +497614520714 & Accessible online at: \\
$\begin{array}{l}\text { E-mail Information@Karger.de } \\
\text { www.karger.com }\end{array}$ & www.karger.com/onk
\end{tabular}




\section{Introduction}

In patients with cancers of the neck or chest region problems may arise when the patient carries an implantable cardioverter-defibrillator (ICD) or cardiac pacemaker when undergoing radiation therapy. This concomitant occurrence of an ICD and an indication for radiation therapy to the respective region has not been frequently observed yet; however, an increase is expected due to an aging population and due to advances in medical technology. Currently, the clinical experience with these cases is very limited. While the first generation of pacemakers was more resistant to ionizing radiation, the newer ICD devices are more sophisticated and demonstrate a higher precision. These more novel devices are significantly more vulnerable to the effects of ionizing rays on the semiconductor material or to electromagnetic interferences [1, 2]. Malfunction, however, can be dangerous and potentially life threatening for the patient. Very cautious recommendations were issued by the American Society for Therapeutic Radiology and Oncology (ASTRO) in 1990 [3] and by the American Association of Physicists in Medicine (AAPM) in 1994 [4]. The accumulated dose to a pacemaker was recommended not to exceed 2 Gy. However, for most patients with an ICD in a typical location this limit is readily exceeded, thus necessitating a removal of the device and an external ICD prior to radiation therapy. These guidelines, however, are well over 10 years old and only based on the experience with the usually more simplistic older pacemakers. Currently, new generations of ICD are being used. In addition, efforts are made by radiation oncologists to escalate radiation dose to achieve higher cure rates. The information provided by the manufacturers of the devices is usually not helpful in this respect. They are very cautious about maximum applicable irradiation doses for an ICD due to the fear of claims for compensation.

We report the case of a patient in whom the dose limit to an implanted ICD was exceeded and demonstrate our medical and technical management.

\section{Case Report}

An extended local recurrence of a laryngeal cancer was diagnosed in a 67-year-old man. Staging demonstrated a pT4 pN2b tumor. For the past 25 years the patient had also experienced severe cardiac problems making the implantation of an ICD necessary. A DDD-RD St. Jude Medical Atlas DR was implanted.

We created a 3D multifield plan. An added dose-volume histogram (DVH) was created for the ICD (fig. 1). Despite all efforts it was impossible to reduce the expected radiation to the ICD to less than a cumulative dose of $2.5 \mathrm{~Gy}$ due to the close proximity to the tumor region. Irradiation was administered conventionally 5 days a week with a multileaf linear accelerator and 6 MV photons from January 2005 until March 2005. A 4-field technique was applied. The extended tumor and lymphatic regions were irradiated up to 36 Gy. Subsequently, we used a preserving technique for the spinal cord for an additional dose of $14 \mathrm{~Gy}$. Only the former tumor region was further treated with single doses of $2.0 \mathrm{~Gy}$ up to a dose of $10.0 \mathrm{~Gy}$. A cumulative dose of $60.0 \mathrm{~Gy}$ was achieved.

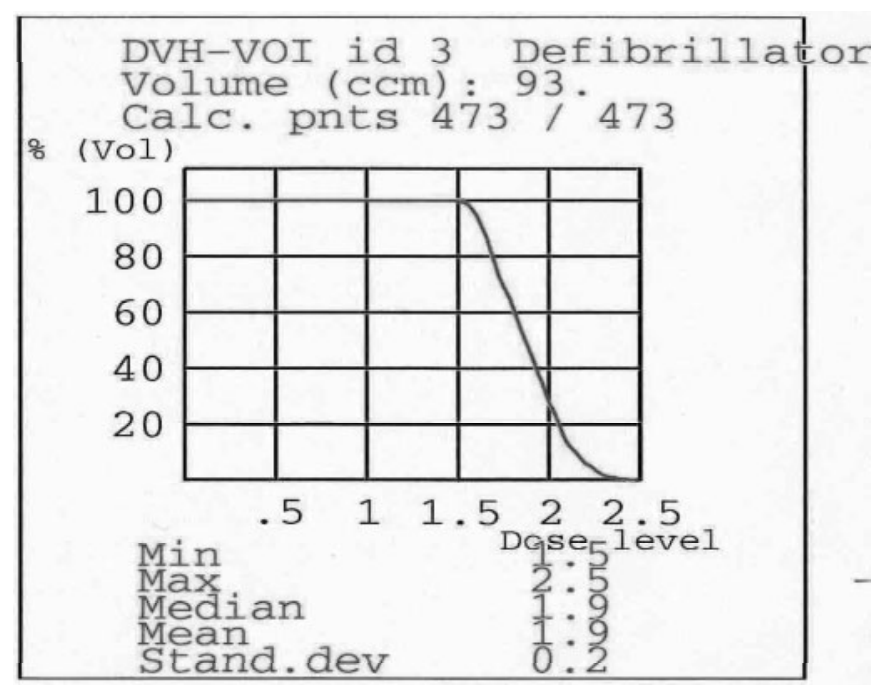

Fig. 1. The pretreatment added dose distribution shows that the defibrillator received a maximum dose of $2.5 \mathrm{~Gy}$. DVH $=$ Dose-volume histogram.

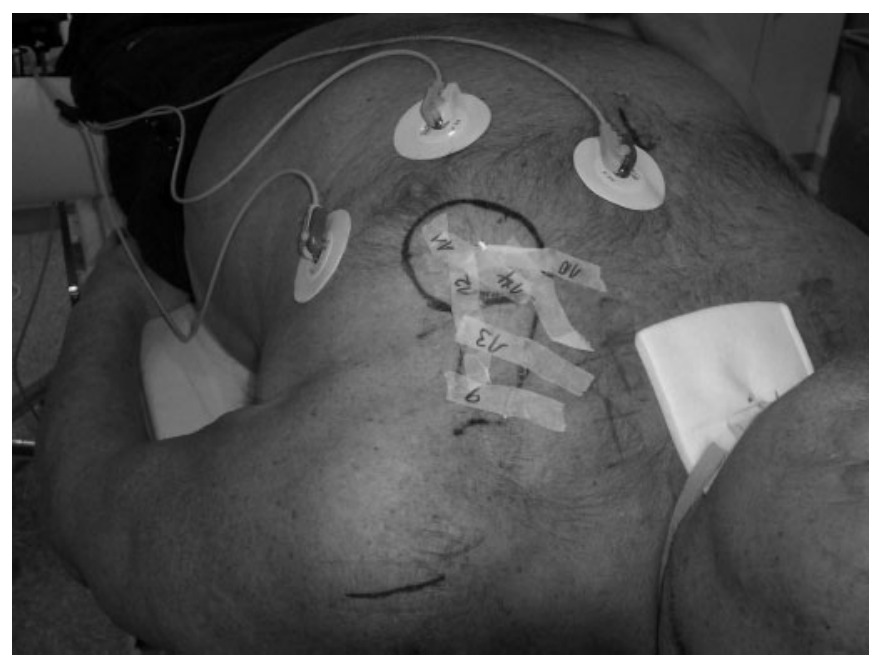

Fig. 2. The implantable cardioverter-defibrillator is under the marked circle. The numbers show the thermoluminescence dosimeters. The field margin from the lymphatical region reaches approximately to the lower margin of the tracheal bandage.

We placed a magnet measuring $2.0 \times 5.0 \mathrm{~cm}$ onto the ICD for deactivating the device directly prior to the irradiation sessions. The patient was connected to an ECG unit, which was monitored from the control room. A radiation oncologist was present at all times in case of an emergency to remove the magnet from the ICD. This step could reactivate the ICD. On the first day of radiation therapy we performed thermoluminescence (TL) measurements in order to control for scattered radiation in vivo. Single dosimeters were grouped around the ICD after it had been marked with colors. Photographs of the single dosimeters were taken for the purpose of easier classification of data (fig. 2). These measurements were taken as a base for calculating the radiation for the extended field. Later, a second TL measurement was carried out. This measurement was representative for the field reduction. Additionally, the patient underwent cardiologic checkups on a regular basis. 
It was possible to administer the radiation therapy without interruption or complications. $5 \mathrm{cGy}$ scattered radiation was measured in the center of the ICD for one irradiation treatment. $9 \mathrm{cGy}$ was measured on the ventral and lateral margin of the ICD. The second measurement after field reduction showed 3 cGy centrally. The margins demonstrated ranges between 5 and $7 \mathrm{cGy}$. In total, this resulted in a cumulative dose of $2.5 \mathrm{~Gy}$ on the ICD for the whole treatment period. The measured TL doses corresponded with the DVH calculated before starting treatment. All cardiologic examinations demonstrated a regular function of the ICD. At the final cardiologic examination, ventricular fibrillation was intentionally induced. The ICD terminated the dysfunction through internal shock with regular charging time. The battery status was in order.

\section{Discussion}

An increase of patients with ICD and simultaneous cancer of the head and neck region requiring radiotherapy is to be expected due to an aging population and due to advances in medical technology. ASTRO [3, 5] and AAPM [4] guidelines are, however, not based on experiences with newer generation ICD devices. The cautious instructions of ASTRO, namely the temporary or permanent removal of the ICD when exceeding $2 \mathrm{~Gy}$, are considered as being too conservative by some authors. Previous reports demonstrated that ICD devices of different manufacturers react differently to irradiation. The administration of high single doses showed that at least 14 Gy could be administered before dysfunction of the ICD [6-8]. Different single and total doses were tested in a water-equivalent phantom with $18 \mathrm{MV}$ photons. Irradiation was administered from 0.05 Gy up to $8.0 \mathrm{~Gy}$ in single doses reaching $200.0 \mathrm{~Gy}$ in total dose. There was a wide range of serious malfunctions. One device was seriously damaged after $0.15 \mathrm{~Gy}$, whereas 10 other devices were treated with over $140.0 \mathrm{~Gy}$ without malfunction $[3,9]$.

Malfunctions of the device can be life threatening for the patient because of reduced reliability to deliver a shock, if needed, or because of uncontrolled shock triggering. The high degree of uncertainty in the treatment of patients with pacemakers or ICD was shown in a representative multicenter study at 75 radiooncological departments in the USA and Canada [10].
A dose of up to $2 \mathrm{~Gy}$ on the cardiac pacemaker or $1 \mathrm{~Gy}$ on the defibrillator is generally considered safe. According to our own experience, however, 1 Gy at an ICD in a typical location is readily exceeded when irradiating a cancer of the neck or chest region.

Since no official guidelines are available for ICD and the prediction of the device's sensitivity to irradiation shows a large variation, we suggest the following proceeding:

The ICD should be outside the irradiation field. Prior to the treatment the estimated scattered radiation dose should be calculated and the risk of an ICD malfunction should be clearly documented in the patient's informed consent, as it is impossible to assess the exact individual risk. The device should be deactivated with a magnet during irradiation. The patient should be monitored with an ECG unit and a physician should be present in case of an emergency. In vivo dosimetric measurements should be performed on the first day of irradiation in order to document scattered radiation. ICD checkup should be performed during the treatment period and thereafter. In our case a total of $2.5 \mathrm{~Gy}$ was tolerated without complications. We were thereby able to avoid a removal of the ICD in the reported case by moderate medical and technical efforts.

\section{Conclusion}

In our case, a patient with an ICD underwent radiotherapy of a head and neck tumor without complications even though 2 Gy were exceeded. No standard protocols are currently available for the new generations of ICD. Since the exact evaluation of the individual risk prior to radiotherapy is not possible, special precautions are necessary. We observed no complications during therapy when adhering to the proceedings proposed in this report with moderate additional effort. We would, however, recommend treatment only at facilities with cardiologic units. We are aware that ours is a single patient experience, but it nevertheless appears to be a practicable option.

\section{References}

1 Last A: Radiotherapy in patients with cardiac pacemakers. Br J Radiol 1998;71:4-10.

2 Hurkmans CW, Scheepers E, Springorum BG, Uiterwaal H: Influence of radiotherapy on the latest generation of implantable cardioverter-defibrillators. Int J Radiat Oncol Biol Phys 2005;63: 282-289.

3 Marbach JR: Recommended precautions in the management of radiation oncology patients with implanted cardiac pacemakers. ASTRO Newsletter 1990;VII:7-8.

4 Marbach JR, Sontag MR, Van Dyk J, Wolbarst AB: Management of radiation oncology patients with implanted cardiac pacemakers: report of AAPM Task Group No. 34. American Association of Physicists in Medicine. Med Phys 1994;21:85-90.
5 Hoecht S, Rosenthal P, Sancar D, Behrens S, Hinkelbein W, Hoeller U: Implantable cardiac defibrillators may be damaged by radiation therapy. J Clin Oncol 2002;20:2212-2213.

6 Maxted KJ: The effect of therapeutic X-radiation on a sample of pacemaker generators. Phys Med Biol 1984;29:1143-1146.

7 Rodriguez F, Filimonov A, Henning A, Coughlin C, Greenberg M: Radiation-induced effects in multiprogrammable pacemakers and implantable defibrillators. Pacing Clin Electrophysiol 1991;14: 2143-2153.
8 Souliman SK, Christie J: Pacemaker failure induced by radiotherapy. Pacing Clin Electrophysio 1994;17:270-273.

9 Mouton J, Haug R, Bridier A, Dodinot B, Eschwege F: Influence of high-energy photon beam irradiation on pacemaker operation. Phys Med Biol 2002;47:2879-2893.

10 Solan AN, Solan MJ, Bednarz G, Goodkin MB: Treatment of patients with cardiac pacemakers and implantable cardioverter-defibrillators during radiotherapy. Int J Radiat Oncol Biol Phys 2004;59: 897-904. 